\title{
Educação Ambiental e
}

\section{alimentação saudável: o despertar dos hábitos na educação infantil}

$\begin{array}{lr}\text { Luciane Cherobini } & \text { Universidade de Rio Grande-FURG, Rio Grande- RS. } \\ \text { Tanise Novello } & \text { E-mail: lucherobini@gmail.com } \\ \text { tanisenovello@furg.br }\end{array}$

Recebido em: 28 maio 2018. Aceito em: 14 out. 2018.

DOI: http://dx.doi.org/10.21674/2448-0479.45.669-684

\section{Resumo}

A prevalência de doenças associadas aos hábitos alimentares, presentes cada vez mais precocemente nas crianças, associada à dificuldade que apresentam quando convidadas a identificar algumas frutas e verduras, além do total desconhecimento de suas procedências, suscita preocupações relacionadas à saúde deste público. Este trabalho apresenta os resultados alcançados em ações promovidas junto aos alunos, familiares e colaboradores de uma escola de educação infantil, localizada no município de Parobé/RS. Assim, este artigo tem como objetivo compreender o que este público entende por alimentação saudável, a partir dos princípios da Educação Ambiental (EA), por meio da escolha de alimentos. Foram desenvolvidas ações como: montagem da pirâmide alimentar com recortes, oficina para a manipulação de alimentos, criação de hortas portáteis, além de atividades que incentivaram a reutilização de resíduos sólidos. Para analisar os registros produzidos durante as oficinas, utilizou-se estudos atuais voltados às áreas envolvidas, que permitiu entender melhor o comportamento das crianças, visto que a inobservância de hábitos saudáveis é um fenômeno contemporâneo que desafia a sociedade. Entre os resultados alcançados, detectou-se tendências positivas à aquisição de novos hábitos alimentares e manifestações de comprometimento com o meio ambiente, que ao início das ações não haviam sido sentidas. Ao final da ação, verificouse que os novos hábitos adquiridos continuaram sendo praticados, observando-se que a valorização do meio ambiente permaneceu nos pequenos gestos das crianças.

Palavras-chave: Hábitos alimentares. Meio ambiente. Crianças. Saúde. 


\section{Abstract \\ Environmental Education and healthy food: awakening the importance of habits in child education}

The prevalence of diseases associated with eating habits, which are becoming increasingly precocious in children, together with the difficulties they present when invited to identify some fruits and vegetables, in addition to the total lack of knowledge of their processes, raises health concerns of this public. This work presents the results achieved in actions promoted with students, family members and employees of a kindergarten school, located in the city of Parobé/RS, and aims to understand what this public understands by eating healthy offering simultaneously notions of Environmental Education (EE), through the choice of food for consumption produced in consonance with the preservation of the environment, offering a contribution to the development of these children and allowing the emergence of the feeling of belonging in the group that composed the study object. Actions were developed such as: assembly of the food pyramid with cutouts, workshop for food handling, creation of portable vegetable gardens, and activities that encouraged the reuse of solid waste. In order to analyze the records produced during the workshops, current studies focused on the areas involved, which allowed a better understanding of the behavior of children, since the nonobservance of healthy habits is a contemporary phenomenon that defies society. Among the results achieved, there were positive trends towards the acquisition of new eating habits and manifestations of compromise with the environment, which at the beginning of the actions had not been felt. At the end of the action, it was verified that the new acquired habits continued to be practiced, observing that the valuation of the environment remained in the small gestures of the children.

Keywords: Eating habits. Environment. Children. health.

\section{Introdução}

A ocorrência precoce de doenças em crianças, antes associadas exclusivamente ao público idoso, desperta a necessidade de investigação do quanto pode contribuir a adoção de hábitos alimentares corretos, assim como a preocupação com a higiene necessária, para a prevenção ou reversão de tal constatação. A possibilidade de intervir nesse processo, mesmo que em escala reduzida, promovendo a Educação Ambiental (EA) a partir de uma alimentação saudável e despertando o cuidado com o meio ambiente foi concretizada em uma escola de educação infantil, localizada no município de Parobé-RS.

As ações, ocorridas no período de agosto a novembro de 2014, se constituíram em: diálogos com alunos, professores e cozinheiras sobre a importância dos hábitos de higiene e da adoção de uma alimentação saudável, considerando-se o que isso significa para a manutenção do meio ambiente; a discussão sobre as principais doenças associadas à má alimentação; a construção de uma horta portátil com a participação dos alunos, professores e familiares, estimulando a produção de 
alimentos e a responsabilidade com o espaço em que se vive; a realização de oficina de culinária com a participação de alunos, professores e cozinheiras a fim de promover alterações nos hábitos alimentares; a confecção de material didático utilizando as embalagens diversas de produtos industrializados utilizados na escola, bem como impressos disponibilizados para a reutilização. Tais ações, acreditava-se, Ihes ajudassem, desde cedo, a desenvolver sentimento de pertencimento ao meio ambiente e lhes demonstrassem a importância de uma relação onde esteja explícito o respeito e a interação com a natureza.

A inclusão de pais e responsáveis no processo mostrou-se contributo valioso e, portanto, o convite foi estendido para que estes viessem a participar na intenção de não ficarem restritas as iniciativas propostas ao ambiente escolar.

O projeto que compreendia reuniões para esclarecer sobre alimentação saudável, oficina culinária, orientações sobre a reutilização de resíduos sólidos, criação e manutenção de hortas portáteis, além da criação de material pedagógico a partir da reutilização, objetivou, fundamentalmente, a promoção da EA. Para tanto, seguiu-se o conceito de EA em concordância com a Conferência Intergovernamental de Tbilisi, Geórgia, realizada em 1977, que a definia como uma ação continuada que objetiva desenvolver habilidades e promover mudanças nas atitudes que o indivíduo mantém com o meio em que vive, oportunizando o entendimento das inter-relações entre os seres humanos, suas culturas e seus espaços biofísicos, observando a ética necessária nas tomadas de decisões que devem priorizar uma melhora na qualidade de vida (BRASIL, 2014).

A extemporaneidade verificada no surgimento de doenças em crianças desperta maior atenção e a necessidade de uma intervenção profilática é avaliada por Pellanda (2011), que atribui esse processo a uma incidência maior de fatores de risco, entre os quais, a obesidade.

[...] Assim, a abordagem do curso da vida permite pensar na prevenção como um processo que se inicia ainda intraútero com a nutrição materna e um cuidado prénatal adequados, e continua ao longo da infância e da adolescência, com o desenvolvimento de hábitos saudáveis e o envolvimento de toda a família na prevenção da instalação dos fatores de risco. Intervenções nessas fases mais precoces da vida podem apresentar um impacto significativo no futuro (PELLANDA, 2011, p. 2).

Se avanços socioestruturais foram experimentados no Brasil das últimas décadas, alcançando dimensões significativas observando-se o quanto foi conquistado em saneamento básico, vacinação e tantos outros programas que atendem às necessidades da população, na contramão, novos hábitos foram adquiridos, entre os quais, a inserção do consumo de alimentos industrializados por parte das crianças, o que promoveu um aumento nos casos de obesidade infantil e, consequentemente, de outras Doenças Crônicas Não Transmissíveis (DCNTs), que colocaram em estado de alerta as autoridades.

Segundo dados de 2009 do Sistema de Informação sobre Mortalidade, as DCNTs concentravam $72 \%$ do total de óbitos no país, percentual que representava mais de 742 mil mortes no ano. As que mais mataram, à época, eram as doenças cardiovasculares $(31,3 \%)$, o câncer $(16,2 \%)$, as doenças respiratórias crônicas $(5,8 \%)$ e o diabetes mellitus $(5,2 \%)$. No Rio Grande do Sul, foram considerados 
70.110 casos de obesidade entre os óbitos registrados em 2009 (BRASIL, 2010). Profissionais da área da saúde projetavam um quadro alarmante: "Pela primeira vez na história da humanidade, com exceção de épocas de guerras, a geração atual viverá menos que a geração de seus pais" (ECKEL et al., 2005, p. 1866).

Considerando-se que o cuidado com a própria saúde está diretamente associado com a EA, visto que a degradação do sujeito é também destruição ambiental (CARVALHO, 2002), tornou-se justificável a realização da pesquisa que serviu de base a este trabalho, diante do pressuposto de que a orientação voltada a uma alimentação saudável adquirida na infância ajudaria a prevenir os hábitos alimentares que determinam a predisposição a enfermidades, tais como: hipercolesterolemia, diabetes, aumento no nível de triglicerídeos, etc. (STÜRMER, 2004).

As questões ecológicas e os graves efeitos da ação predatória do homem sobre o planeta e sobre sua própria espécie fizeram com que a atenção à saúde se voltasse a um contexto mais amplo, onde as relações estabelecidas com o ambiente físico e social necessitam ser levados em conta para que se possam estabelecer novos rumos a fim de preservar a vida com qualidade.

Se observada a função transformadora que tem a EA em sua permanente investigação pelo desenvolvimento sustentável, visualiza-se o quanto uma alimentação saudável é capaz de contribuir para que o indivíduo desenvolva a percepção de sua participação nesse processo, visto sua intervenção direta na valorização da saúde e, consequentemente, na conservação ambiental. Nesse exercício, conveniente se torna lembrar o que comenta Carvalho (2005, p. 58):

\begin{abstract}
Politicamente, um dos traços distintivos do educador ambiental, parece ser partilhar, em algum nível, de um projeto político emancipatório. A ideia de mudanças radicais abarca não apenas uma nova sociedade, mas também um novo sujeito que se vê como parte desta mudança societária e a compreende como uma revolução de corpo e alma, ou seja, uma reconstrução do mundo incluindo o mundo interno e os estilos de vida pessoal.
\end{abstract}

Entende-se, aqui, que nada pode ser mudado exteriormente se algumas das atitudes que precisam ser revistas ainda estão interiorizadas, enraizadas e, assim, permanecerão se não houver a coragem necessária para fazê-lo.

Ao se verificar os hábitos extraescolares do público pesquisado, um perfil heterogêneo revela distintas atitudes em relação à alimentação. Se em alguns casos se evidencia a preocupação com o consumo de nutrientes que compõem uma alimentação saudável, em outros se vê a inexistência de atenção nesse sentido, o que oportuniza, muitas vezes, a ingesta de produtos industrializados (salgadinhos, biscoitos recheados, etc.) em detrimento do habitual "feijão com arroz", pela simples praticidade do trabalho se restringir ao abrir de uma embalagem.

Ao se projetar a amplitude dos benefícios capazes de serem alcançados a partir de uma alimentação saudável, é possível vislumbrar não somente uma melhoria no desempenho físico daqueles que a adotam - o que, por si só, já justificaria - mas, também, pela economia significativa 
que isso representaria. Conforme o Guia Alimentar para a População Brasileira, uma alimentação equilibrada pode contribuir para a diminuição de despesas voltadas à saúde pública (BRASIL, 2014).

A Constituição Federal de 1988, em seu Artigo 225, preconiza que o meio ambiente ecologicamente equilibrado é direito de todo cidadão, assim como é de responsabilidade do poder público e da coletividade o dever de defender esse bem comum e essencial à qualidade de vida saudável a fim de preservá-lo para as gerações atuais e futuras (BRASIL, 1988). Instituída, em 27 de abril de 1999, a Política Nacional de Educação Ambiental (PNEA), em seu Artigo 2ª prevê que "A educação ambiental é um componente essencial e permanente da educação nacional, devendo estar presente, de forma articulada, em todos os níveis e modalidades do processo educativo, em caráter formal e não formal" (BRASIL, 1999).

Considerada tema transversal pelos Parâmetros Curriculares Nacionais (PCN's), a EA é integrante de uma proposta de interdisciplinaridade (BRASIL, 1997a), onde a comunicação é instrumento capaz de promover a interação a fim de elucidar a realidade.

\footnotetext{
Ao buscar um saber mais integrado e livre, a interdisciplinaridade conduz a uma metamorfose que pode alterar completamente o curso dos fatos em educação; pode transformar o sombrio em brilhante e alegre, o tímido em audaz e a esperança em possibilidade (FAZENDA, 2008, p. 46).
}

Ao se pensar em alimentação saudável associada à EA vislumbra-se uma amplitude imensurável, a partir da oportunidade de criar novos hábitos nas crianças em idade pré-escolar tendo como objetivo visualizar em cada uma delas um cidadão comprometido consigo e com o planeta.

As atividades programadas para atingir esses objetivos propostos fundamentaram-se em literatura voltada à Nutrição e à Educação Ambiental, em reunião de autores que corroboram a necessidade de introdução dos dois temas junto ao público infantil, defendendo a ideia de que quanto mais precocemente esse processo for iniciado, mais chances existirão de se alcançar resultados positivos.

\section{Metodologia: ações e produção de dados}

A pesquisa que fundamentou este trabalho, quanto à abordagem, mostrou-se quali-quantitativa, pois utilizou o ambiente natural como fonte direta para a coleta de dados e procurou traduzir em números os conhecimentos gerados (PRODANOV; FREITAS, 2009), fazendo, também, o uso de consulta bibliográfica como procedimento técnico para embasar o estudo de caso.

A Escola de Educação Infantil onde se deu a execução do projeto localiza-se no perímetro urbano do município de Parobé/RS, atende 64 crianças, em turno integral (06h às 18h30min). Em dois prédios, estão instaladas cinco salas de aula, secretaria, cozinha, lavanderia e biblioteca. No pátio externo existem brinquedos que compõem o playground. 
O universo pesquisado para a coleta de dados constituiu-se de uma população composta por 12 alunos da educação infantil, na faixa etária entre 4 e 6 anos. Foram realizadas observações in loco, além da distribuição de questionários - anteriores e posteriores ao projeto -, entregues aos pais dos alunos, que reuniram dados sobre os hábitos alimentares em seu ambiente familiar para posterior avaliação. Optou-se pela utilização de questionários, visto que se tratam de instrumentos desenvolvidos cientificamente, compostos de perguntas ordenadas de acordo com critérios predeterminados e respondidos sem a presença do entrevistador (MARCONI; LAKATOS, 2003).

Por meio de oficina de culinária e considerando-se o interesse típico da idade das crianças participantes pelo preparo e manipulação de alimentos, foi proposta a participação de todas na elaboração de receitas saudáveis, com orientações e esclarecimentos sobre a composição nutricional, procedência dos ingredientes, higiene e a destinação dos resíduos orgânicos.

É possível considerar como sujeitos envolvidos diretamente na pesquisa os alunos já mencionados, cuja população compunha-se de cinco do sexo masculino e sete do sexo feminino, além da professora que acompanha a turma, as cozinheiras que preparam a alimentação servida na escola e as diretoras, que além de disponibilizar o espaço físico, equipamentos e ingredientes para a oficina prática, acompanharam o desenvolvimento de todas as atividades direcionadas ao projeto.

Faz-se necessário computar os familiares dos alunos como sujeitos alcançados pelas ações, visto que a amplitude das experiências realizadas com as crianças acabaram por propagar-se em seus ambientes domésticos.

Atividades propostas para a execução do projeto ficaram restritas ao espaço físico da escola e permitiram às crianças um primeiro contato com a EA, a partir do conceito de que a preservação do corpo e a escolha dos alimentos ingeridos estão relacionadas diretamente à atenção que se dispensa ao ambiente.

Foi realizada uma reunião com as professoras para exposição do projeto. Mostrou-se, com o uso de apresentação em PowerPoint ${ }^{\circledR}$, material referente à Alimentação e Saúde que, a partir da conceituação de Nutrição e Alimentação, introduziu a Pirâmide Alimentar, as doenças mais comuns relacionadas à má alimentação (obesidade infantil, desnutrição, hipercolesterolemia, diabetes, aumento no nível de triglicerídeos, etc.), a importância da higiene correta com os alimentos e, finalizando, foram explicadas as fases do comportamento alimentar na infância, além dos critérios que necessitam ser observados como, por exemplo, a resistência a algum alimento. Cabe ressaltar que as participantes demonstraram total interação com o que foi apresentado, pois viram, na ocasião, oportunidade para adquirir novos conhecimentos que poderiam ser aproveitados, inclusive, em seus ambientes domésticos, oferecendo aos seus filhos um primeiro contato com a EA.

Uma explanação destinada aos pais teve como objetivo a interação da família nas atividades propostas, onde dados sobre enfermidades associadas à alimentação deficiente esclareceu sobre a importância do exemplo oferecido às crianças na manutenção de hábitos saudáveis. A ocasião mostrou-se oportuna para salientar a importância que tem a EA e a promoção de atitudes que colaborem com a preservação do meio em que vivem, visto serem os pais o primeiro contato que essas crianças têm com a interdependência entre o ser humano e a natureza que o provêm, enquanto preservada. 
Com o objetivo de conhecer os hábitos alimentares e o comportamento das crianças em seu ambiente familiar (Figura 1), um primeiro questionário pré-elaborado foi encaminhado aos pais dos alunos. Um segundo questionário seria encaminhado aos pais, ao final das atividades práticas, com o intuito de avaliar se algumas alterações foram verificadas no comportamento alimentar dos participantes (Figura 2).

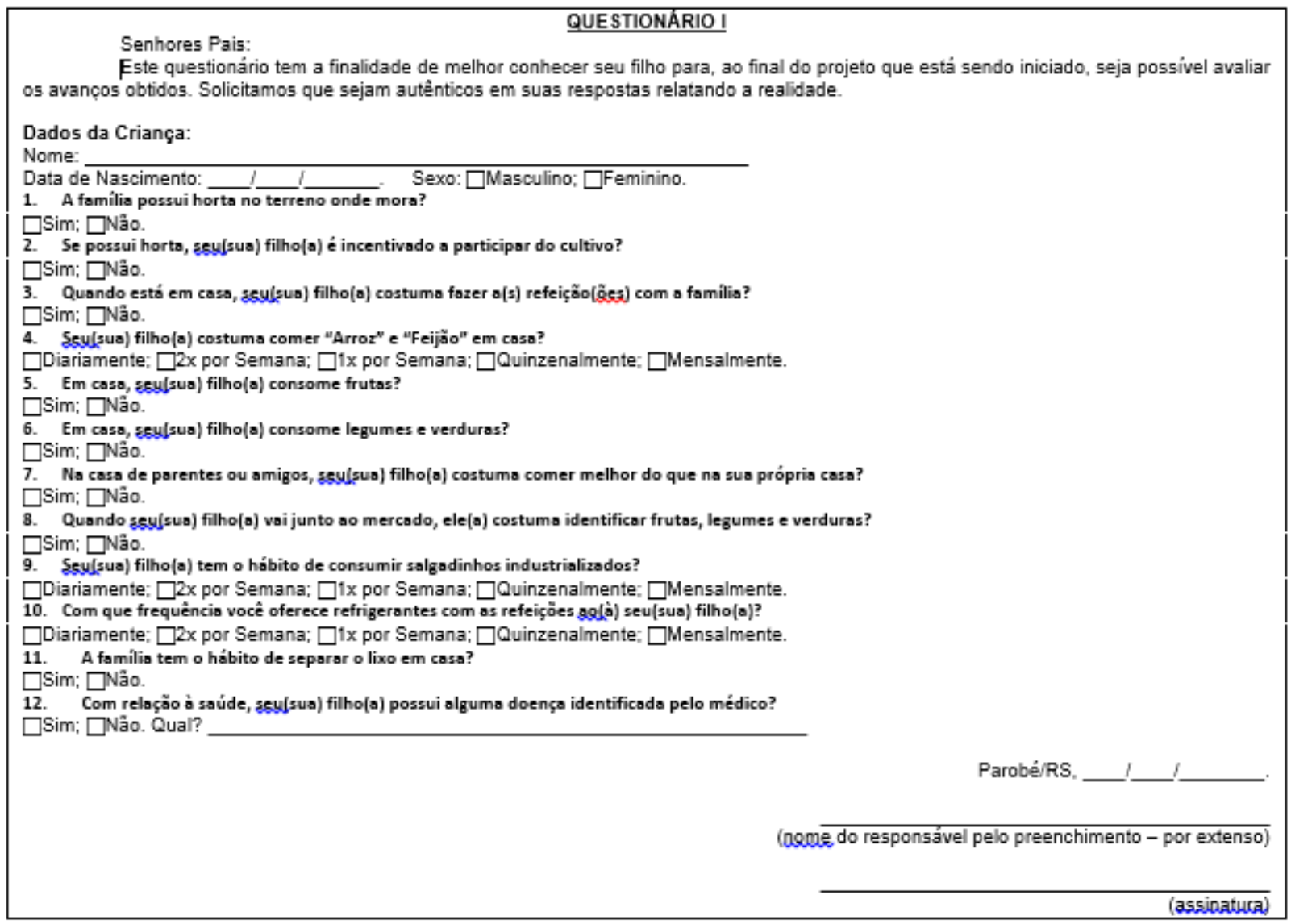

Figura 1 - Primeiro questionário aplicado (Fonte: Elaborado pelas autoras) 


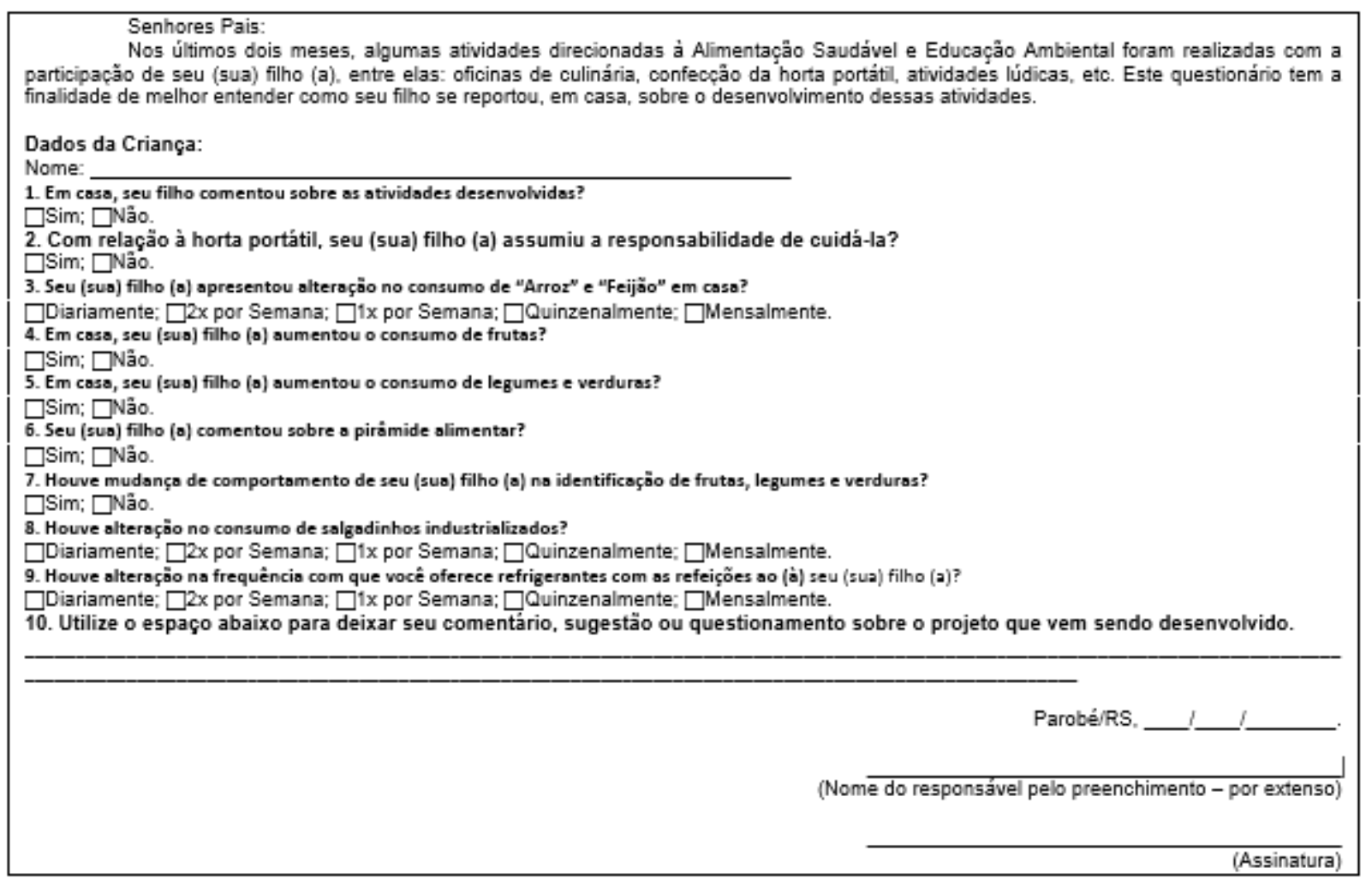

Figura 2 - Segundo questionário aplicado (Fonte: Elaborado pelas autoras)

Convidada a participar, a professora titular da turma desenvolveu atividade, com o uso de material gráfico, que tinha como objetivo apresentar aos alunos a pirâmide alimentar e os grupos de alimentos que a compõem. As crianças demonstraram interesse e curiosidade sobre o assunto, manifestando suas preferências alimentares, o que possibilitou elaborar a próxima atividade, com a intenção de vencer a resistência demonstrada por algumas quanto ao consumo de legumes, principalmente à cenoura. Na sequência, através da distribuição de ilustrações, foi promovida a pintura com lápis de cor dos alimentos vistos na pirâmide como forma de familiarização com cores e nomes dos mesmos. Uma exposição foi organizada para a afixação dos trabalhos dos alunos.

Foi realizada uma oficina de culinária que procurou estimular o contato com alimentos que as crianças apresentavam resistência. Para tanto, promoveu-se a confecção de espetinhos que reunissem alimentos como: queijo, ovo de codorna, tomate cereja e cenoura. Cada criança montou um espetinho sob a supervisão da professora titular e da nutricionista (Figura 3). Foi observado que, excetuando-se um integrante do grupo que tem acentuada resistência a diversos alimentos, todas as demais crianças consumiram os alimentos que compunham seus espetinhos, inclusive a cenoura que é comum sofrer resistência à grande maioria. Com o objetivo de proporcionar às crianças a oportunidade de partilhar com a família a experiência até então adquirida, cada aluno recebeu uma cópia da pirâmide alimentar para colorir. Após, colaram recortes de folders de supermercados contendo produtos nos seus devidos lugares conforme suas preferências, preenchendo os andares da pirâmide. A seguir, montaram através de encaixe uma pirâmide em papel-cartão para levar para casa (Figura 4). Foi interessante observar que durante a realização desta atividade, as crianças compartilhavam com os colegas o conhecimento que haviam adquirido. 


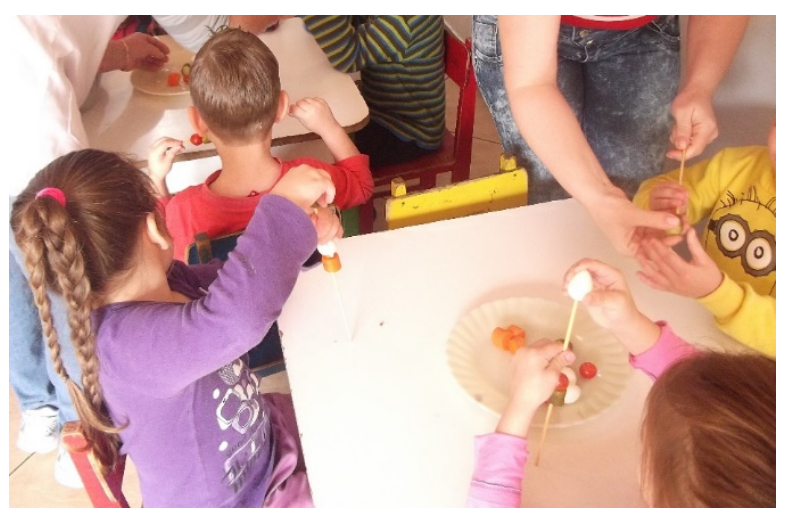

Figura 3 - Espetinhos saudáveis

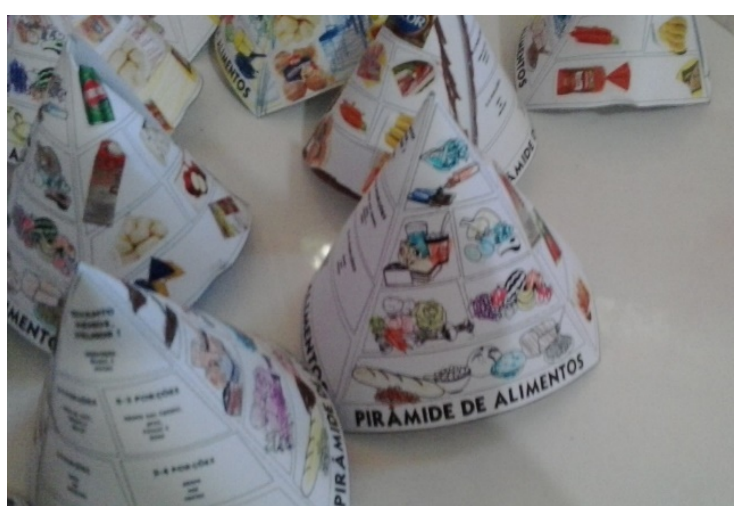

Figura 4 - Colorindo e pintando a Pirâmide Alimentar

Para preparar a turma para a confecção da horta portátil, foi realizada a hora do conto com a história Coelhinho e a Cenoura Mágica (SEGERS; D'HAMERS, 2009). Foram reunidas as crianças para ouvirem uma história infantil que tem como tema a produção de hortaliças e entendessem como funciona o cultivo de alimentos. A história relata a rotina em uma comunidade de coelhos onde se cultiva o hábito de plantar diversos tipos de hortaliças com a finalidade de participar de uma competição entre os produtores. A receptividade das crianças à história foi gratificante, pois todos aceitaram o desafio de trazer de casa um recipiente para cultivar cada um sua própria horta portátil e acompanhar o crescimento de suas hortaliças, atividade que foi programada para o encontro seguinte.

Com a intenção de oferecer a oportunidade de contato com o plantio e manutenção de hortaliças em uma horta portátil, solicitou-se às crianças que, com a participação de seus pais, encontrassem e trouxessem recipientes capazes de receber uma plantinha que ficaria sob seus cuidados. Foram reunidos os recipientes trazidos de casa pelos alunos, distribuída a terra para plantio e as mudas de alface (Lactuca sativa), previamente cultivadas (Figura 5). Cada criança foi convidada a preparar seu recipiente e plantar a muda. Foi lembrada às crianças a responsabilidade que cada uma passava a ter com o vegetal plantado, visto tratar-se de um ser vivo que necessitaria de cuidados, pois tratá-lo passaria a fazer parte de sua rotina. Cada criança regou sua plantinha e reservou-a para que aguardasse a ida para casa. Notou-se que a expectativa em torno da atividade foi grande, pois todos os alunos aguardavam ansiosamente o momento de utilizar o material que usariam para realizar o plantio. Houve total interação e chamou atenção a preferência que as crianças demonstraram na utilização de ferramentas confeccionadas com material reutilizável em detrimento das ferramentas de jardim tradicionais compradas em ferragem. 


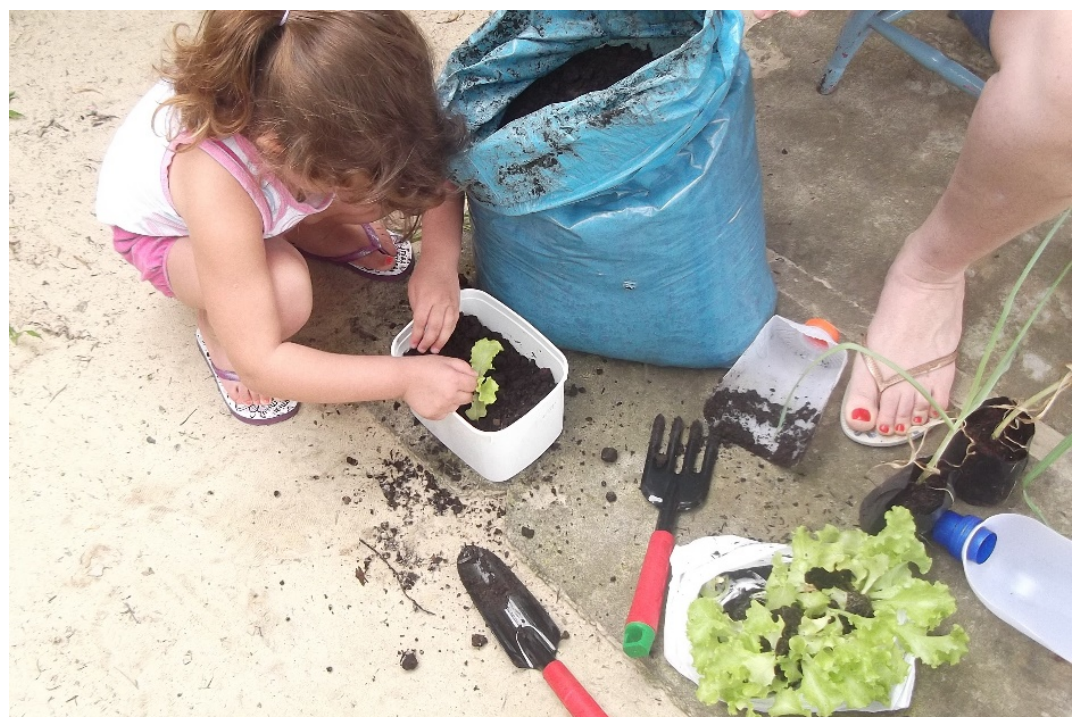

Figura 5 - Horta portátil

Após a realização das atividades previstas, procurou-se avaliar se algumas mudanças comportamentais alimentares teriam sido manifestadas e, para isso, utilizou-se como instrumento de pesquisa o segundo questionário, que foi encaminhado aos pais das crianças.

\section{Resultados e Discussão}

A projeção dos resultados que seriam alcançados tornou-se clara a partir dos primeiros encontros com as professoras da educação infantil, que aderiram ao projeto com total engajamento e participação. Com o propósito de melhor expor os avanços alcançados na realização do projeto, apresentam-se a seguir a interpretação dos resultados obtidos.

Entre o grupo de crianças pesquisado, em resposta ao primeiro questionário, quando perguntado se a família tinha o habito de separar o lixo orgânico do lixo seco em casa, 8 (oito) responderam que sim e 4 (quatro) disseram que não. Perguntados se possuíam horta no terreno onde moravam, as respostas afirmativas somaram 5 (cinco) sendo 7 (sete) as respostas negativas e, entre as famílias que plantam hortaliças e leguminosas em seus domicílios, $80 \%$ dos pais incentivam as crianças a participar das atividades de cultivo.

Observou-se no questionamento dirigido aos pais que $25 \%$ do grupo de alunos não tinham como hábito o consumo de frutas, legumes e verduras nas refeições em casa, mas que somente dois deles $(16,7 \%$ do total) não identificavam esse tipo de produto quando acompanhavam os pais ao supermercado.

Quanto ao hábito de consumir produtos industrializados, foi verificado que um integrante do grupo consumia salgadinhos diariamente, quatro o faziam duas vezes por semana, três consumiam uma vez por semana, dois quinzenalmente e dois mensalmente. Sobre as refeições serem acompanhadas por refrigerantes, um dos participantes revelou que oferece ao seu filho diariamente, três deles o fazem duas vezes por semana, seis oferecem uma vez por semana, um quinzenalmente e um mensalmente. 
Quando perguntado sobre a saúde das crianças, três crianças têm doenças detectadas, entre as quais rinite, amigdalite e tosse alérgica, enquanto nove não sofrem de nenhuma doença identificada pelo médico.

É importante mencionar como aspectos relevantes: o contato proporcionado às crianças com elementos que compõem o meio ambiente, o convite à soma de conhecimentos trazidos do ambiente familiar com a proposta de experimentar o "mexer na terra", o fazer algo novo que as fez refletir sobre sua capacidade de ação na mudança de hábitos que contribuem para a preservação do planeta. Foram gratificantes alguns resultados imediatos, como a aceitação dos alimentos que sofriam alguma resistência, assim como o companheirismo demonstrado entre as crianças durante a execução das atividades e o interesse visualizado na expectativa que todas estampavam quando uma nova atividade era proposta.

Em trabalhos que abordam experiências semelhantes, direcionadas a crianças em escolas, Pimenta e Rodrigues (2011), Fernandes et al. (2013) e Santos (2014) relatam resultados que corroboram com os aqui apresentados, partilhando registros de mudanças de hábitos alimentares decorrentes de práticas na produção de hortaliças associada à educação ambiental.

No presente estudo, os resultados obtidos com o segundo questionário, posterior às práticas, permitiram detectar que a totalidade dos alunos envolvidos no projeto teve interesse em partilhar as experiências desenvolvidas, fazendo comentários e demonstrando entendimento do conteúdo das atividades com seus familiares, interagindo cada vez que a oportunidade surgia. Fato passível de observação quando se verifica que a maioria das crianças e seus pais adotaram a pirâmide alimentar e passaram a consultá-la na hora de identificar os grupos que a compõem com a alimentação que era oferecida. O que pode ser ilustrado pelos comentários de uma mãe:

"Acho o projeto bem importante, a pirâmide que ela fez fica na cozinha e sempre uso para mostrar a ela a importância de comer alimentos saudáveis e tem ajudado bastante" (Mãe 01).

Observa-se que a informação trazida pela criança é compartilhada com os demais membros da família, recebe atenção e acolhimento, passando a ser considerada como ingrediente da rotina na hora da alimentação. A mãe demonstra a intenção de aproveitar a oportunidade para vencer alguma resistência que persistia na filha de aceitar alguns alimentos que the são oferecidos.

Com relação ao comportamento na fase pré-escolar, assim como a influência que podem exercer os familiares na criação de padrões alimentares, Stürmer $(2004$, p. 76$)$ afirma que

[...] vários estudos referem que as preferências alimentares das crianças são os principais determinantes de sua ingestão, e esse processo é aprendido por experiências repetidas, onde os fatores ambientais exercem papel importante na criação do padrão alimentar, seja ele adequado ou não.

O papel da família, considerado fundamental, conforme Macedo, Bello e Palha (2002), contribui para o processo de desenvolvimento psicológico da criança numa reunião de tipos de comportamento que a criança assume diante da alimentação. Esses comportamentos, segundo os autores, tendem a seguir um padrão que, sendo detectado, deve receber atenção especial. 
[...] Se não for criada uma boa relação alimentar, a relação mãe-filho pode ser prejudicada e a criança passa a não comer para chamar a atenção ou impor sua vontade (MACEDO; BELLO; PALHA, 2002, introdução).

Essa relação alimentar a que os autores se referem precisa ser entendida como o estabelecimento de momentos que permitam tornar a ocasião da alimentação em situação onde se consiga associar o hábito de se alimentar a um evento que proporciona prazer. Sobre estímulos e observações que podem auxiliar no entendimento do comportamento infantil, Ctenas e Vitolo (1999, p. 67) explicam que "[...] o desenvolvimento utiliza inteligência, mas não pode ser confundido com ela. Todas as crianças precisam ser estimuladas para adquirir habilidades básicas, importantes para seu convívio social, ou seja, se desenvolverem adequadamente".

Há, portanto, um consenso que preconiza a necessidade de um comportamento dos adultos de maneira estável e capaz de gerar segurança, pois as boas relações da criança dependem da atitude dos pais, que deve ser correta, não só na hora das refeições, mas durante todo o tempo.

Sobre a mudança de hábitos alimentares, foi observado a partir da realização das atividades uma aceitação maior de verduras, legumes, sucos naturais, bem como de algumas frutas que antes não faziam parte da alimentação das crianças, tanto na escola como nos seus domicílios. Pimenta e Rodrigues (2011, p.10) acrescentam a existência de "[...] ganhos positivos com resultados esperados alcançados, através de mudanças alimentares e consumo diário pelos alunos e de pais, que relataram que passaram a consumir hortaliças devido às cobranças dos filhos". Nos depoimentos das mães acrescentam-se outras observações:

"Eu achei o desenvolvimento da L. muito melhor do que antes ela comia em casa. Eu acho que ela está bem melhor" (Mãe 02).

Entenda-se neste testemunho que a criança passou a apresentar menor resistência aos alimentos oferecidos, fato que ocorreu em continuidade à sua participação na oficina realizada, na qual foi lembrada a procedência dos alimentos servidos, além da preocupação que se deve ter com o processo pelo qual passa cada ingrediente de uma receita desde sua produção até ser servido à mesa.

"Bom, para o E. foi bom, pois ele não comia verduras. Agora come tomate, alface, cenoura, frutas. Gosta muito de banana e principalmente maçã. Pede para fazer refeições que são servidas na escolinha. Venho aqui agradecer o empenho de todos" (Mãe 03).

Verifica-se neste episódio que o propósito de inserção de vegetais na alimentação da criança, a exemplo de outros casos onde a resistência era observada, obteve pleno êxito, visto que além da mudança de comportamento, há a proposta de alteração no cardápio das refeições, em casa, com a sugestão de que este acompanhe aquele servido na escola. Aqui, cabe a reflexão de que a validade de um projeto só pode ser mensurada quando se questiona sua contribuição para reverter alguma situação que se considera equivocada e se verifica quantos avanços já foram alcançados.

"A D. comenta sobre os trabalhinhos que ela faz na creche, e passou a comer saladas e legumes" (Mãe 04).

A modificação de hábitos alimentares, que levam a uma nutrição equilibrada, não tem a configuração de uma ação espontânea, visto que exige reflexão e persistência por parte de pais, Rev. Elet. Cient. UERGS, v.4, n.5, p. 669-684, 2018. 
familiares e educadores que se dispuserem a esse comprometimento. Esse processo, na concepção de alguns autores, deve ter início na infância para que os seus efeitos sejam satisfatórios. Angelis (2003, p. 67) afirma: "[...] quanto mais cedo os hábitos saudáveis forem ensinados, melhor será a manutenção futura, sem a sensação de ser um castigo".

É possível afirmar que a alimentação está relacionada às questões ambientais, visto que o incentivo à utilização de frutas, cereais, leguminosas, verduras e alimentos caseiros nas refeições, contribui, diretamente, com a ideia que preconiza a validade do alimento natural à mesa como forma de garantir a diminuição do uso de energia não renovável nos processos de industrialização, uma menor produção de lixo com difícil decomposição - como é o caso das embalagens plásticas - e a promoção da saúde tão necessária a todos.

Com relação à horta portátil, somente um aluno transferiu a responsabilidade de sua manutenção aos pais, enquanto o restante do grupo manifestou preocupação em cuidar do desenvolvimento da plantinha, fato constatado no parecer a seguir:

"Achamos muito importante esse desenvolvimento com os nossos pequenos. O G. cuidou da alface dele, mas ela morreu, ele ficou todo preocupado, mas expliquei a ele que isso é normal acontecer" (Mãe 05).

Em estudo semelhante, Fernandes et al. (2013) registraram o estímulo ao consumo de hortaliças observado em crianças que cultivaram as verduras utilizadas em suas preparações culinárias, ao produzi-las de forma orgânica e, consequentemente, com alto valor nutritivo.

Referindo-se ao cultivo dos alimentos - quer em pequenos espaços ou não - e à atitude esperada das crianças quando têm sob sua tutela o desenvolvimento de uma vida, Gadotti (1998, p. 98) comenta que:

[...] um pequeno jardim, uma horta, um pedaço de terra, é um microcosmo de todo mundo natural. Nele encontramos forma de vida, recursos de vida. Processo de vida. A partir dele podemos reconceitualizar nosso currículo escolar. Ao construí-lo e cultivá-lo podemos aprender muitas coisas. As crianças o encaram como fonte de tantos mistérios! Ele nos ensina os valores da emocionalidade da Terra: a vida, a morte, a sobrevivência, os valores da paciência, da perseverança, da criatividade, da adaptação, transformação, da renovação.

É possível enxergar no simples ato da criança chamar para si a proteção de uma plantinha, que simboliza fragilidade e dependência, entre outras propriedades, uma atitude solidária cuja amplitude pode contribuir sobremaneira na construção dos valores éticos que lhe guiarão por toda a vida. Desenvolver nesta mesma criança a capacidade de assimilar a contribuição que será capaz de oferecer ao meio ambiente acaba por se apresentar tarefa que se executará sem muita dificuldade, visto as primeiras experiências já terem lhe oferecido o contato com o respeito que deve oferecer à natureza.

Crespo (1998) afirma que para se sensibilizar grupos, principalmente de crianças, há necessidade da utilização de práticas aplicadas em ambientes abertos que lhes facilite o contato com a natureza de forma que sintam e visualizem o que está sendo falado. Sobre o espaço aberto, Fernandes et al. (2013, p. 76) explicam que o cultivo de hortaliças faz com que esses locais assumam Rev. Elet. Cient. UERGS, v.4, n.5, p. 669-684, 2018. 
outras funções: "A horta pode ser um laboratório vivo, que integra diferentes atividades didáticas".

Gadotti (2005) acrescenta que não seria possível aprender a amar o planeta somente lendo livros sobre isso, pois é a experiência pessoal que tem o poder de levar o indivíduo a cultivar este sentimento. Dessa forma, o despertar para a EA passaria, obrigatoriamente, pelas experiências proporcionadas com as práticas que levem as crianças ao questionamento do espaço físico a que estão habituadas para, a partir disso, tentarem entender o macroambiente em que estão inseridas.

Salvo raras exceções, a criança dos dias atuais não se preocupa em saber de onde vêm ou como foram produzidos os alimentos, muitas julgam que sua origem está associada às embalagens que encontram no supermercado. Essa realidade promove um afastamento da criança em relação ao meio ambiente, que não se vê como parte dele, muitas vezes, influenciada pelo ambiente familiar que não desenvolve nela o sentimento de pertencimento, tão necessário ao exercício da cidadania.

Um resultado que precisa ser considerado de grande valia é a constatação de que os alunos passaram a demonstrar maior observação com relação às plantas pertencentes ao ambiente escolar, conforme relato da professora. Isso leva à reflexão de que a importância de um lugar está intrínseca ao sentimento de pertencimento que o indivíduo Ihe dedica, pois, segundo Lestingue (2004, p. 50), "[...] se sinto-me pertencente, me liberto". A partir dessa identificação, o indivíduo se torna agente da preservação e manutenção, não por determinação ou imposição de alguém, mas pela sua própria conscientização enquanto produtivo na sua coexistência com o semelhante.

Necessário se faz, porém, descaracterizar esse sentimento de pertencimento como retrocessão, visto que em muitas situações acontece esta associação. Pertencer a um lugar não significa estagnar o processo desenvolvimentista que se apresenta em significativo avanço para cultuar hábitos e atitudes remanescentes de culturas ancestrais retrógradas em nome de uma suposta - e falsa - ideia de preservação.

\section{Considerações finais}

Não haveria como negar que o projeto desenvolvido ampliou o horizonte que se projetava como cenário para a prática de EA, pois novos atores foram sendo somados e acabaram de uma maneira ou outra contribuindo para que a ideia tomasse corpo e a iniciativa conquistasse o comprometimento de todos os envolvidos. As atividades realizadas oportunizaram um contato maior com o grupo de crianças aos quais o projeto se dirige que, dentro de suas particularidades, souberam assimilar novos conhecimentos às experiências pessoais, apesar de limitadas à idade que têm, assim como despertar em seus familiares a necessidade de estimular em seus filhos a preocupação com o meio em que vivem e como proceder quanto à alimentação para que se mantenham saudáveis.

Ao acompanhar a evolução no comportamento das crianças, fica evidente que os objetivos foram alcançados e, aquém da expectativa, outros resultados positivos podem ser citados. Exemplo disso é que: a descoberta de que a alface não nasce dentro de um saquinho plástico no supermercado foi, para uns, impressionante, para outros, uma decepção; uma revelação fácil de assimilar é que o contato tátil com uma cenoura pode ser menos dolorido que uma injeção; o odor da terra onde se 
plantam as alfaces pode ser considerado pior do que o exalado pela fralda do seu irmão menor; fica mais fácil de entender que "aquela coisa" que serviam na merenda da escola, depois que se aprende a fazer, vira uma gostosura.

Há, é claro, que se considerar que a reeducação alimentar exige, desde sua implantação até definitivamente inserida entre os hábitos do indivíduo, demanda razoável de tempo e disposição para mudanças. Exatamente como se apresenta a EA que, segundo Loureiro (2007, p. 159), "não é um movimento linear e automático de sair de um padrão para outro, mas dinâmico, pelo qual superamos limites identificados ao longo da existência".

Importante é sentir que os resultados do projeto implantado continuam sendo verificados, pois nos contatos mantidos com as crianças da escola de educação infantil, cenário desta ação, constatase que os hábitos alimentares que sofreram mudanças permanecem sendo praticados, a valorização do meio ambiente continua sendo observada nos pequenos gestos, nas atitudes corriqueiras, e credita-se parte significativa do sucesso alcançado aos familiares e professoras que não deixaram de lado os objetivos traçados.

Se a criança é o reflexo da geração que sucede, é preciso enxergar adiante, promovendo mudanças agora, com o olhar direcionado às atitudes que ela irá deixar às gerações que legará ao futuro. É com este pensamento que se acredita o projeto iniciado tenha a expectativa de frutificação, levando-se em consideração que a direção e corpo docente da escola, onde teve sua implantação realizada, já demonstram interesse em ampliá-lo às demais turmas de alunos nos próximos semestres.

Se observado for que a EA tem por premissa uma visão holística sobre o indivíduo e suas atitudes em relação ao meio em que vive, é possível vislumbrar que alguns passos foram dados na execução deste trabalho ao se verificar que, por menor que pareçam, alguns comportamentos sofreram mudanças, alguns conceitos passaram a ser revistos e, certamente, novos questionamentos passarão a existir no pensamento das crianças envolvidas, que as farão refletir sobre a importância que têm os seus atos.

\section{Referências}

ANGELIS, R.C. Riscos e prevenção da obesidade: fundamentos fisiológicos e nutricionais para tratamento. São Paulo: Atheneu, 2003.

BRASIL. Constituição da República Federativa do Brasil. Edição da Assembleia Legislativa do Rio Grande do Sul. Porto Alegre: CORAG, 1988.

BRASIL. Ministério da Educação e Cultura (MEC); Secretaria de Educação Fundamental (SEF). Parâmetros curriculares nacionais: apresentação dos temas transversais, ética. Brasília: MEC/SEF, 1997a. Disponível em: <http://portal.mec.gov.br/seb/arquivos/pdf/ livro081.pdf>. Acesso em: 30 mar. 2018.

BRASIL. Ministério da Saúde. Guia alimentar para a População Brasileira. 2. ed. Brasília: Ministério da Saúde, 2014.

BRASIL. Presidência da República; Secretaria para Assuntos Jurídicos. Lei nº 9.795, de 27 de abril 
de 1999. Dispõe sobre a educação ambiental, institui a Política Nacional de Educação Ambiental e dá outras providências. Disponível em: <http://www.planalto.gov.br/ccivil_03/ leis/19795.htm>. Acesso em: 28 mar. 2015.

BRASIL. Ministério da Saúde. Rede Interagencial de Informações para a Saúde - RIPSA. Indicadores e Dados Básicos - IDB. 2010. Disponível em: <http://tabnet.datasus.gov.br/cgi/idb2010/ matriz.htm\#morb>. Acesso em 01 jun. 2014.

CARVALHO, I.C.M. A invenção ecológica: sentidos e trajetórias da educação ambiental no Brasil. 2. ed. Porto Alegre: EDUFRGS, 2002.

CARVALHO, I.C.M. A invenção do sujeito ecológico: identidades e subjetividade na formação dos educadores ambientais. In: SATO, M.; CARVALHO, I.C.M. (Orgs) Educação Ambiental: pesquisa e desafios. Porto Alegre: Artmed, 2005

CRESPO, S. Educar para a sustentabilidade: a educação ambiental no Programa da Agenda 21. In: NOAL, F.O.; REIGOTA, M.; BARCELOS, V.H. Tendências da Educação Ambiental Brasileira. Santa Cruz do Sul: EDUNISC, 1998.

CTENAS, M.L.B.; VITOLO, M.R. Crescendo com saúde: o guia de crescimento da criança. São Paulo: C2 Editora e Consultoria em Nutrição Ltda., 1999.

ECKEL, R.H. et al. America's children: a critical time for prevention. Circulation, Dallas, v.111, p.18661868, 2005. Disponível em: <http://circ.ahajournals.org/content/ 111/15/1866. full.pdf+html>. Acesso em: 02 abr. 2015.

FAZENDA, I.C.A. O que é interdisciplinaridade? São Paulo: Cortez, 2008.

FERNANDES, M. O. et al. Horta na escola: incentivando hábitos saudáveis de alimentação em uma escola de Uberlândia-MG. Em Extensão, Uberlândia, v.12. n.2, p.75-83, jul./dez. 2013. Disponível em: <www.seer.ufu.br/index.php/revextensao/article/download/ 22610/13539>. Acesso em: 20 jul. 2018.

GADOTTI, M. Pedagogia da Terra. São Paulo: Ed. Peirópolis. 1998.

GADOTTI, M. Pedagogia da terra e cultura da sustentabilidade. Revista Lusófona da Educação, Lisboa, v.6, n.6, p.15-29, 2005. Disponível em: <http://www.scielo.oces.mctes.pt/pdf/rle/n6/ n6a02.pdf>. Acesso em 02 abr. 2015.

LESTINGUE, S.R. Olhares de educadores ambientais para o estudo do meio e pertencimento. Tese (Doutorado) - Escola Superior de Agricultura Luiz Queiroz, Universidade de São Paulo, São Paulo, 2004. Disponível em: <http://www.teses.usp.br/teses/disponiveis/ 11/11150/tde-03022005155740/>. Acesso em 29 mar. 2015

LOUREIRO, C.F.B. Emancipação. In: FERRARO JR., L.A. (Org.) Encontros e caminhos: formação de Educadoras(es) Ambientais e Coletivos Educadores. Brasília: MMA, Diretoria de Educação Ambiental, 2007. v.2, p.157-170. Disponível em: <http://www.mma.gov.br/ estruturas/educamb/_arquivos/encotros_2.pdf>. Acesso em: 01 jun. 2014.

MACEDO, C.A.P.; BELLO, K.L.; PALHA, L.A.G. A criança que não come: guia de tratamento e prevenção. São Paulo: Atheneu, 2002.

MARCONI, M. de A.; LAKATOS, E.M. Fundamentos de metodologia científica. 5. ed. São Paulo: Atlas, 2003

PELLANDA, L.C. Determinantes precoces das doenças cardiovasculares no curso da vida: uma mudança de paradigma para a prevenção. Revista da Associação Médica Brasileira, São Paulo, v.57, n.6, dez. 2011. Disponível em: <http://www.scielo.br/ scielo.php?script=sci_arttext\&pid=S010442302011000600002 \&lng=en\&nrm=iso>. Acesso em: 28 jun. 2014. 
PIMENTA, J.C.; RODRIGUES, K. da S.M. Projeto Horta Escola: ações de educação ambiental na escola Centro Promocional Todos os Santos de Goiânia (GO). Anais. II SEAT-Simpósio de Educação Ambiental e Transdisciplinar, Goiânia, maio 2011. Disponível em:

<https://portais.ufg.br/up/52/o/29_Horta_na_escola.pdf>. Acesso em: 20 jul. 2018.

PRODANOV, C.C.; FREITAS, E.C. Metodologia do trabalho científico: métodos e técnicas da pesquisa e do trabalho acadêmico. Novo Hamburgo: Feevale, 2009.

SANTOS, A.P.R. dos. Implantação da Horta Escolar em uma Escola Pública em Araras (SP). 2014. Monografia [Especialização em Ensino de Ciências] - Universidade Tecnológica Federal do Paraná, Medianeira, 2014. Disponível em:

$<$ http://repositorio.roca.utfpr.edu.br/jspui/bitstream/1/4758/1/MD_ENSCIE_IV_2014-06.pdf >. Acesso em 20 jul. 2018.

SATO, M.; PASSOS, L.A. Notas desafinadas ao saber e do poder: qual a rima necessária à educação ambiental? Contrapontos, Itajaí/SC, v.3, n.1, p.9-26. mar. 2009. Disponível em:

<http://www6.univali.br/seer/index.php/rc/article/view/700/553>. Acesso em: 01 jun. 2014.

SEGERS, G.; D'HAMERS, H. Coelhinho e a cenoura mágica. Trad. Marylene Pinto Michael. São Paulo: Zastras Editora, 2009.

STÜRMER, J.S. Reeducação alimentar na família: da gestação à adolescência. Petrópolis/RJ: Vozes, 2004. 